\title{
POBLACIÓN EN EL MAGREB: SITUACIÓN Y DINÁMICAS
}

\author{
Gracia Abad ${ }^{1}$ \\ Universidad Nebrija / Investigadora UNISCI
}

\begin{abstract}
Resumen:
La situación demográfica de los Estados del Magreb contrasta claramente con la de los Estados del norte del Mediterráneo, como España, pues no sólo muestran claras tendencias de crecimiento de la población sino que tampoco presentan riesgo de envejecimiento de la población hasta, al menos, mediados del presente siglo. Con todo, es innegable que estos Estados podrían estar iniciando una transición demográfica pues algunos indicadores, aunque lentamente, parecen empezar a cambiar. Por otra parte, en los Estados del Magreb sí se estaría produciendo un claro proceso de emigración del campo a la ciudad como consecuencia de la menor calidad de vida existente en las áreas rurales, algo que podría estar contribuyendo a las crecientes tasas de desempleo. Éstas últimas podrían estar fomentando, a su vez, la emigración al extranjero de la población magrebí.
\end{abstract}

Palabras clave: Magreb, población, crecimiento, envejecimiento, Argelia, Marruecos, Túnez.

Title in English: "Maghreb's Population: Current Situation and Dymanics"

\begin{abstract}
:
The demographic situation of the Maghreb States seems to be in sharp contrast with that of the Northern Mediterranean States like Spain. They show a trend of population growth. The population is relatively young and there is no risk of ageing, at least until the second half of this century. All in all, it should be noticed that these States might be at the beginning of a demographic transition as some indicators, albeit slowly, seem to start changing. Besides, the Maghreb States would be experiencing a process of migration from rural to urban areas as a consequence of the lower quality of life in the rural areas. This might be feeding unemployment rates and pushing Maghreb population to migrate to foreign countries.
\end{abstract}

Keywords: Maghreb, population, growth, ageing, Algeria, Morocco, Tunisia.

Copyright (C) UNISCI, 2013.

Las opiniones expresadas en estos artículos son propias de sus autores, y no reflejan necesariamente la opinión de UNISCI. The views expressed in these articles are those of the authors, and do not necessarily reflect the views of UNISCI.

\footnotetext{
${ }^{1}$ La Dr. Gracia Abad es profesora de Relaciones Internacionales en la Universidad Nebrija en Madrid, investigadora senior en UNISCI y es miembro del Foro Hispano-Argelino.

E-mail: graciaabad@yahoo.es.

http://dx.doi.org/10.5209/rev_UNIS.2013.n31.44744
} 


\section{El volumen demográfico de los estados del Magreb: su evolución futura}

A diferencia de lo que ocurre en numerosos casos en la ribera norte del Mediterráneo -es notorio en el caso de España, y en numerosos casos en el mundo desarrollado, los Estados del Magreb no cesan de crecer desde el punto de vista demográfico.

Esta realidad es particularmente visible en el caso de Marruecos, cuya población se encuentra inmersa en una dinámica de franco crecimiento, tal y como muestra el gráfico siguiente:

\section{MARRUECOS}

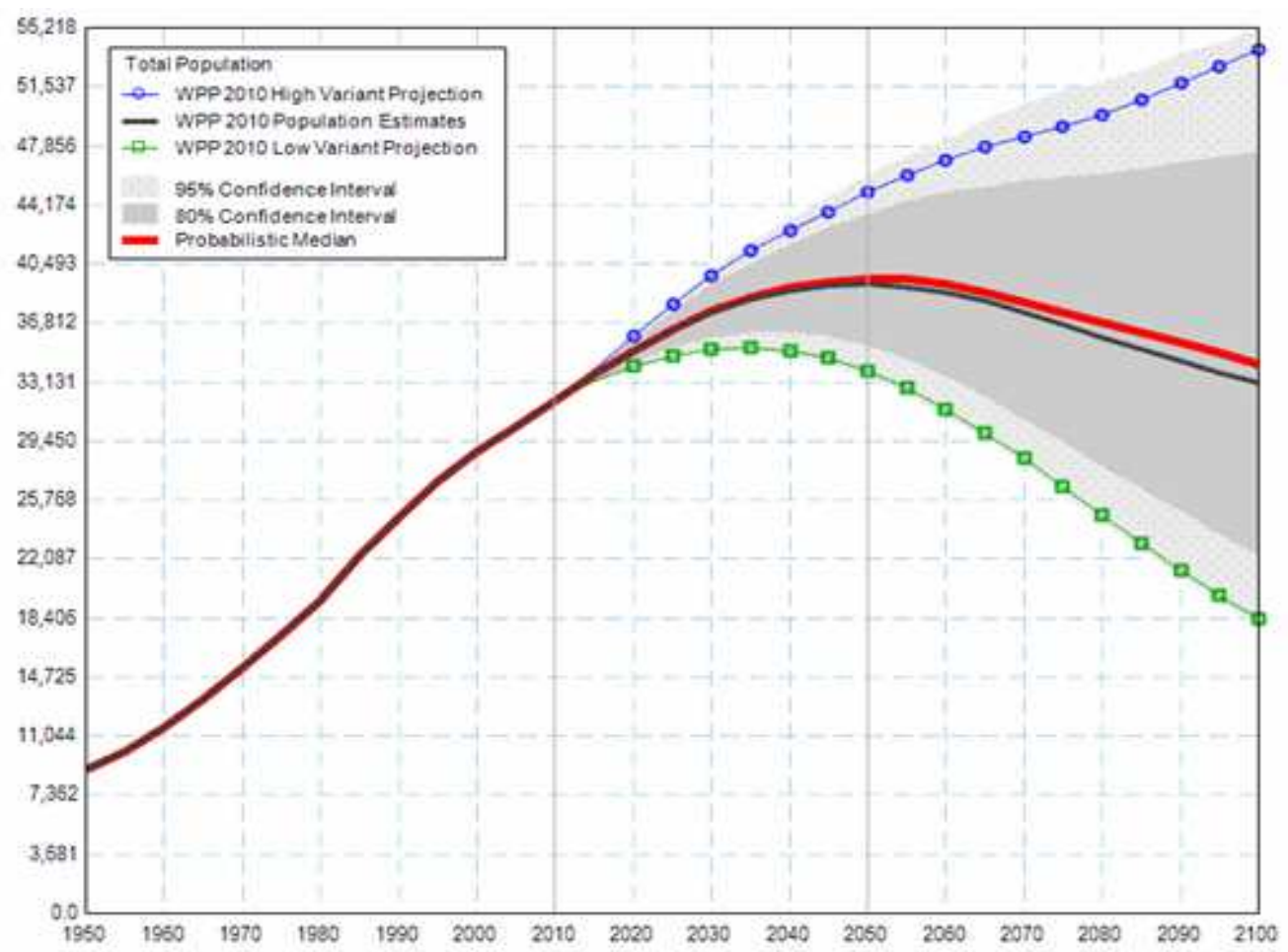

Fuente: UN Population Division

Los casos de Argelia y Túnez son algo distintos, puesto que el ritmo de crecimiento ha sido algo menor hasta el momento, pero como Marruecos se encuentran también en una fase de aumento de la población: 


\section{ARGELIA}

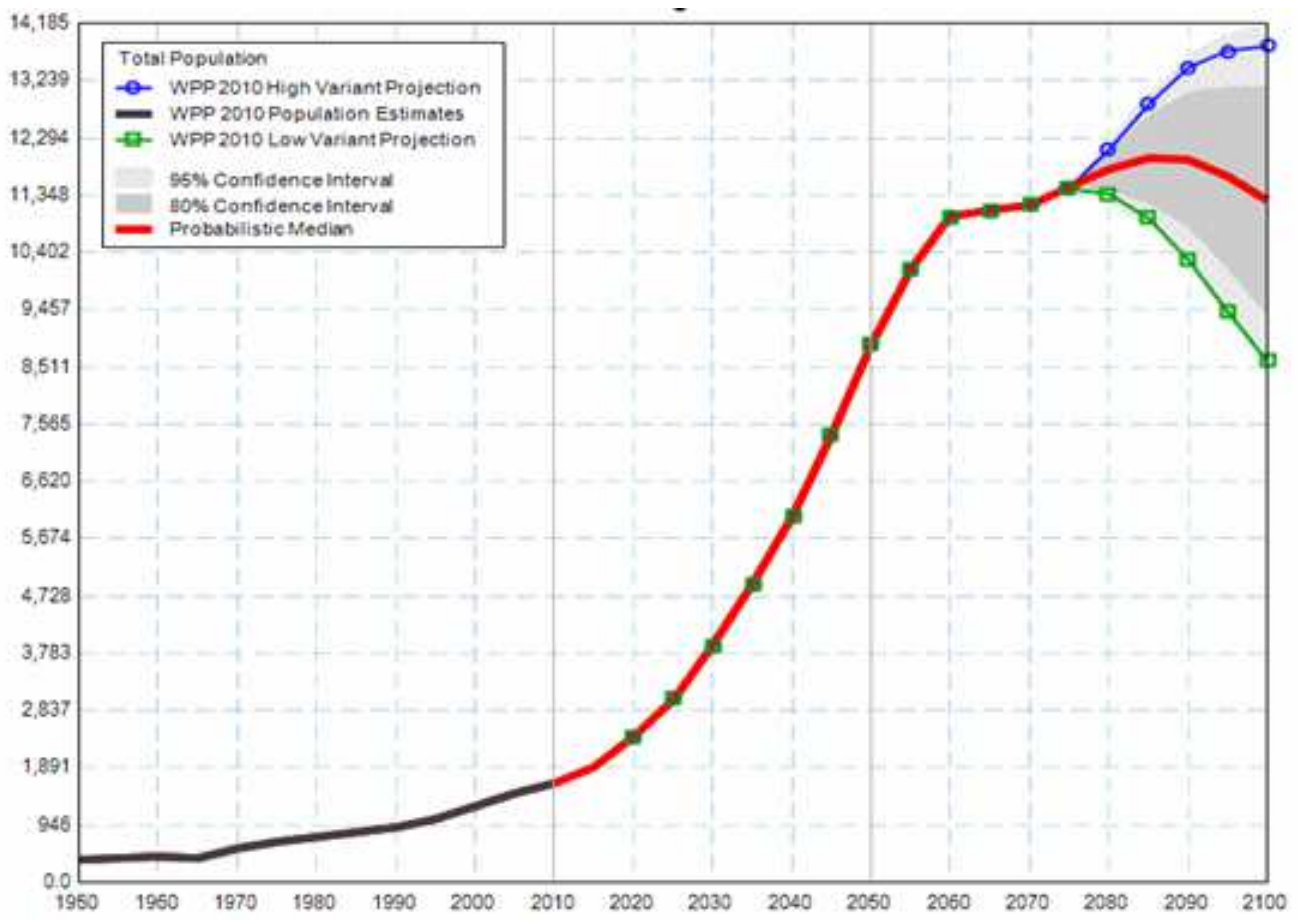

Fuente: UN Population Division

\section{TÚNEZ}

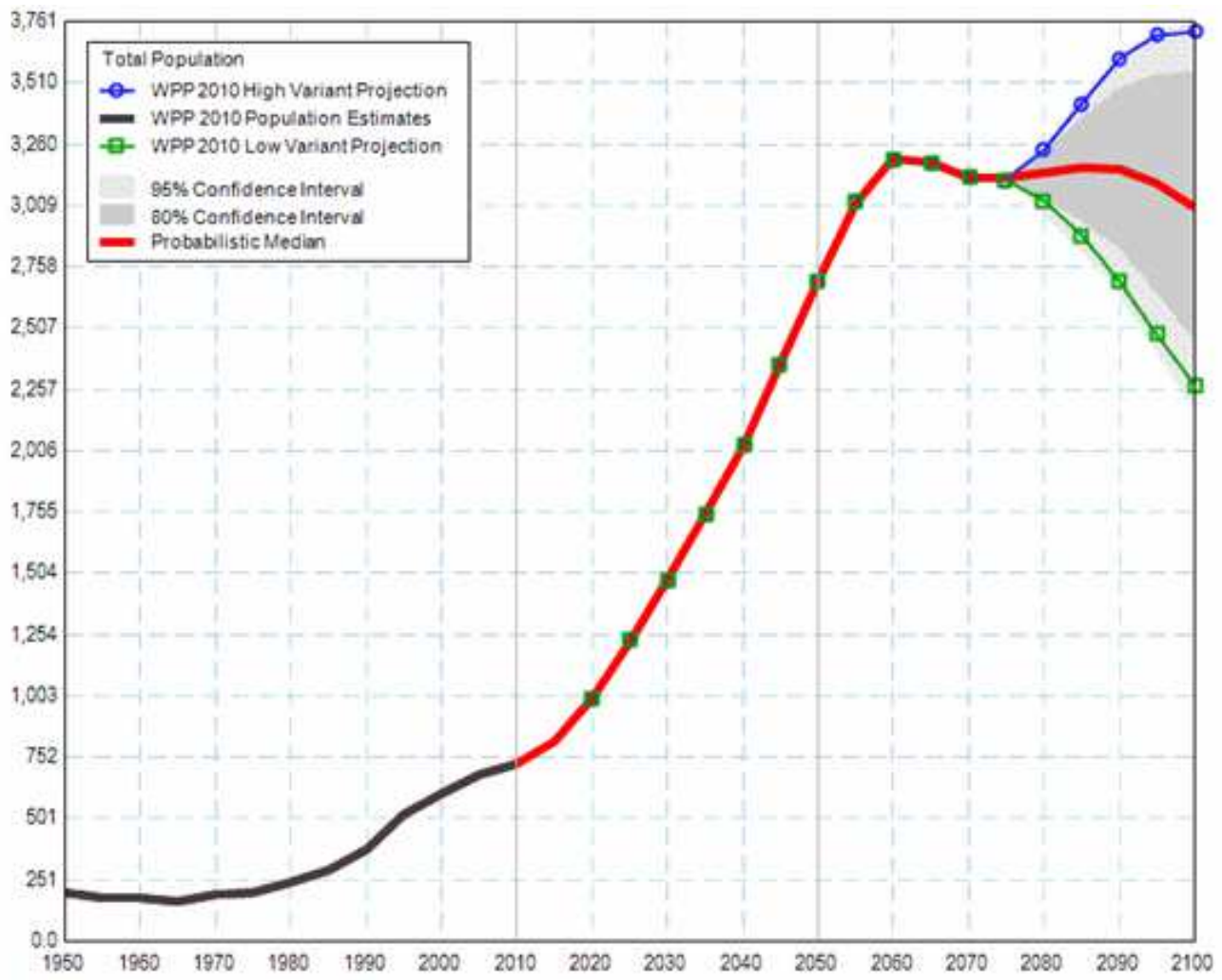

Fuente: UN Population Division 
Por lo demás, todo parece indicar que la tendencia, lejos de invertirse va a continuar en los próximos años, al menos, hasta mediados del presente siglo. Así se ve tanto en los gráficos que acabamos de reproducir como en los que mostramos a continuación:

\section{MARRUECOS}

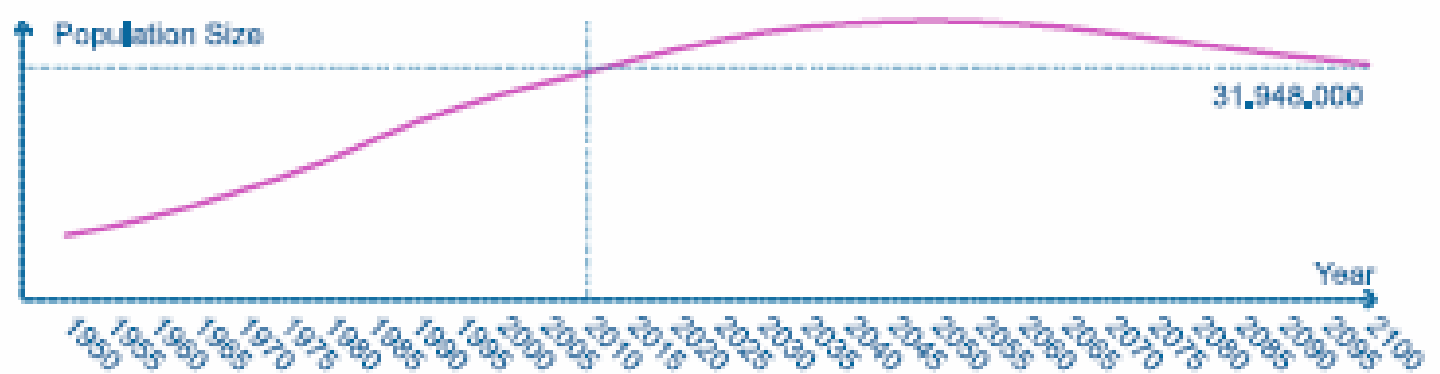

Fuente: Population Pyramid

\section{ARGELIA}

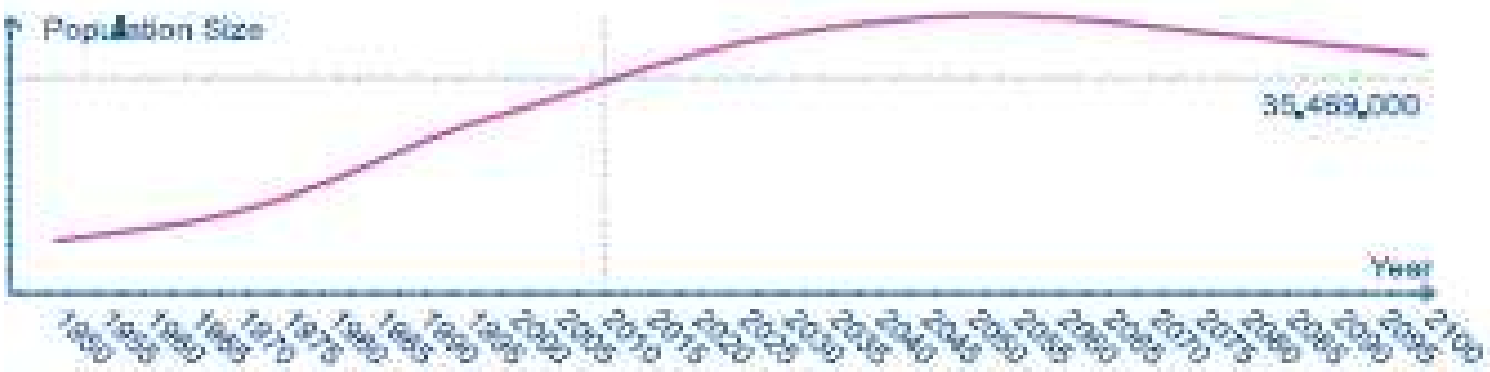

Fuente: Population Pyramid

\section{TÚNEZ}

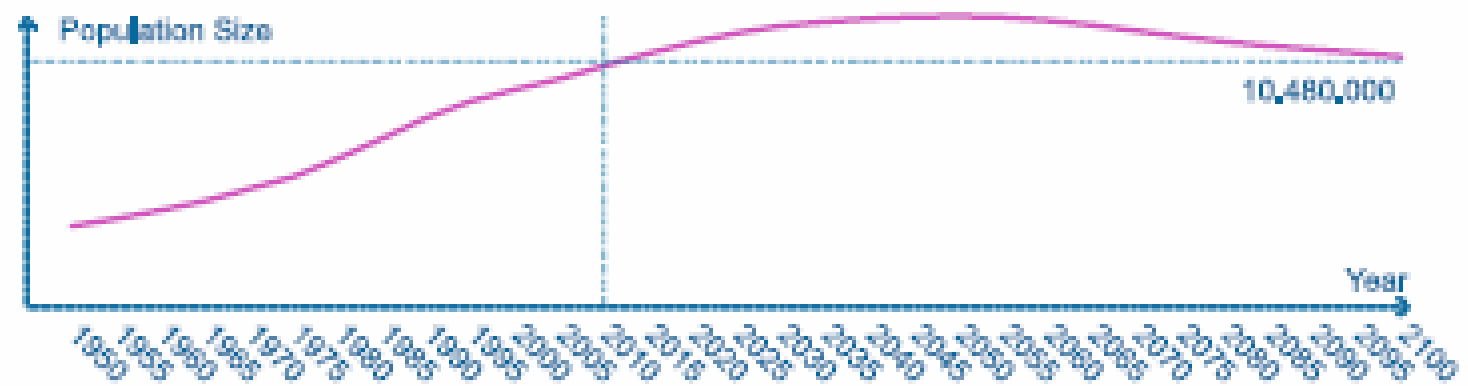

Fuente: Population Pyramid 


\section{La composición de la población en los Estados del Magreb: ¿envejecimiento?}

Por otra parte, la población marroquí no ha experimentado por el momento un envejecimiento digno de mención:

\section{MARRUECOS}

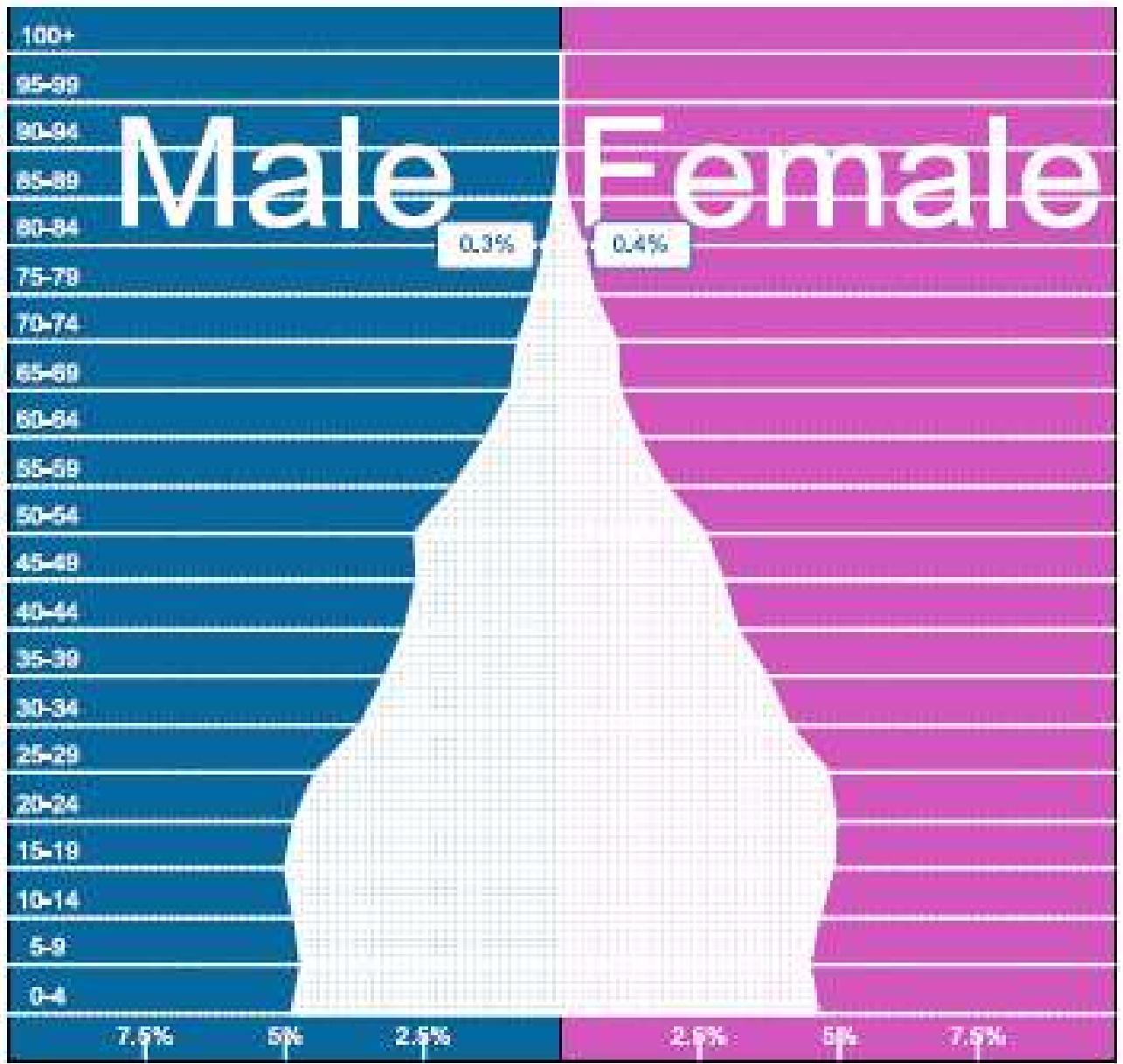

Fuente: Population Pyramid

Es cierto que, si comparamos la composición poblacional actual del país vecino con la que tenía en 1950, se ha producido un cierto envejecimiento, pero éste en ningún modo supondrá un problema para Marruecos en las próximas décadas y sólo será ostensible para la segunda mitad del siglo XXI. Así se aprecia en los gráficos que reproducimos a continuación: 


\section{MARRUECOS}

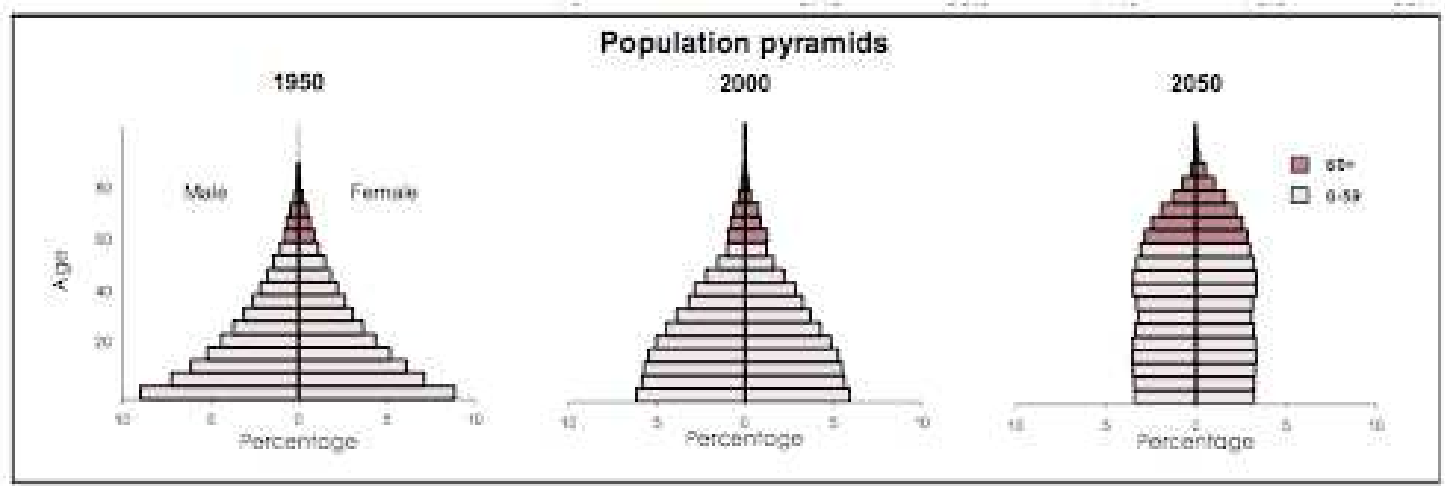

Fuente: Naciones Unidas, DESA

Por su parte, tampoco Argelia muestra señales de envejecimiento de su población ni en el momento actual ni a corto plazo. También en este caso las previsiones de envejecimiento nos llevan a más allá de 2050:

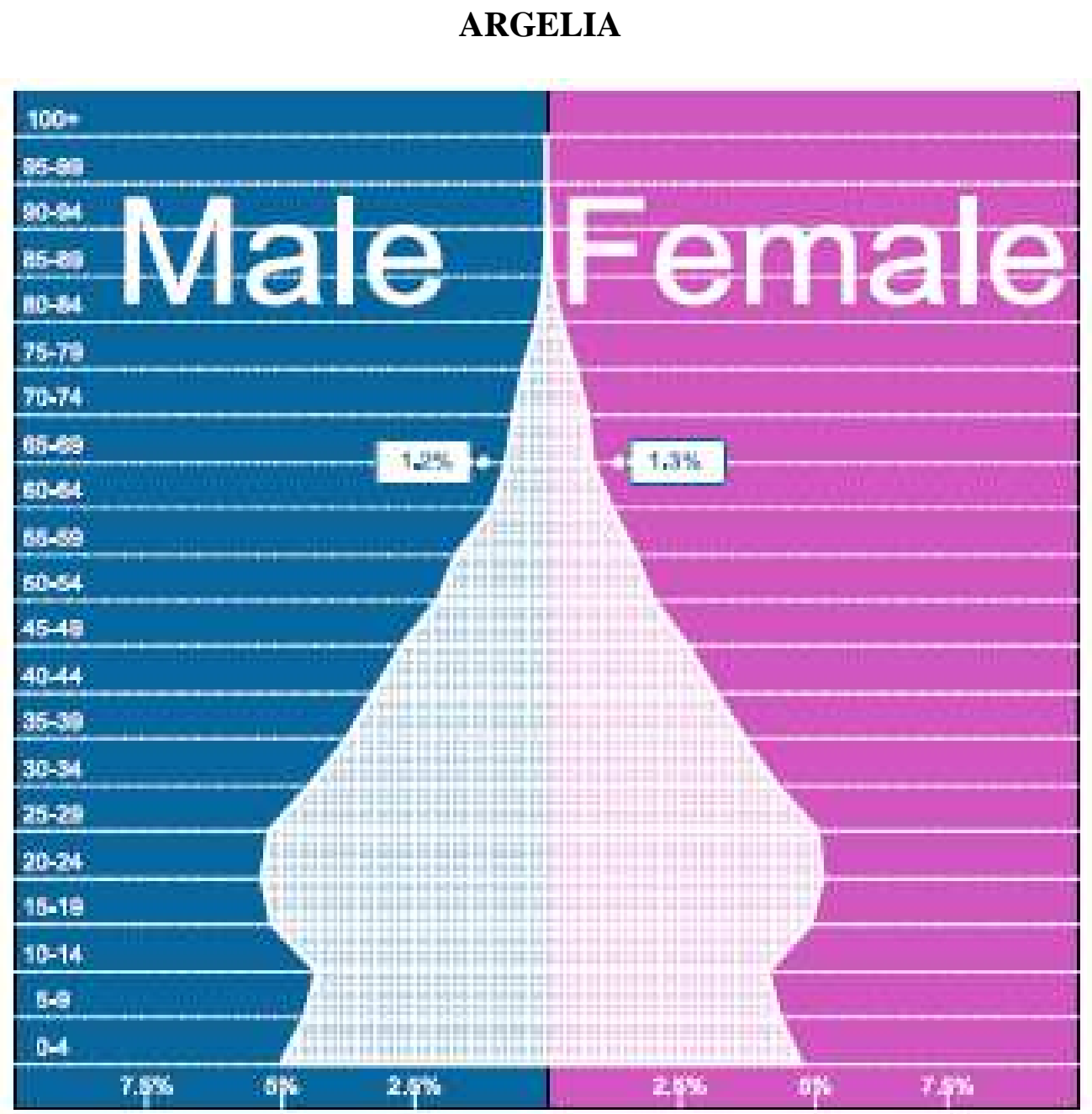

Fuente: Population Pyramid 


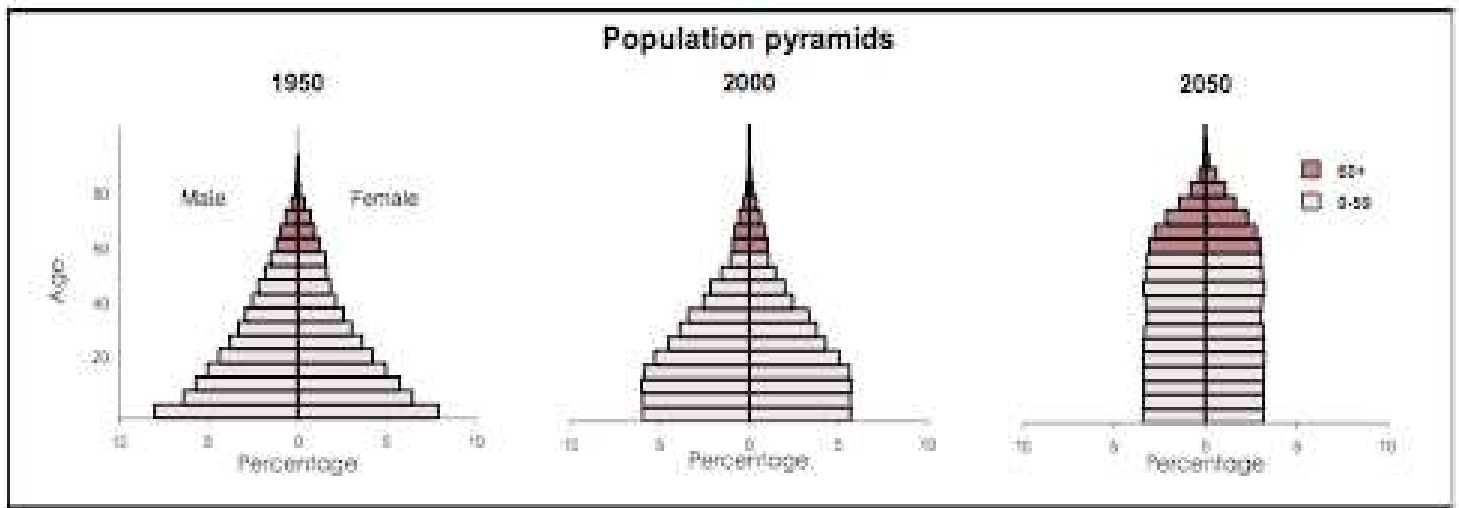

Fuente: Naciones Unidas, DESA

Otro tanto cabe decir del caso de Túnez, que presenta una pirámide poblacional muy similar a la de sus vecinos y donde los problemas derivados del envejecimiento de la población sólo podrían producirse, en consecuencia, desde mediados de este siglo:

TÚNEZ

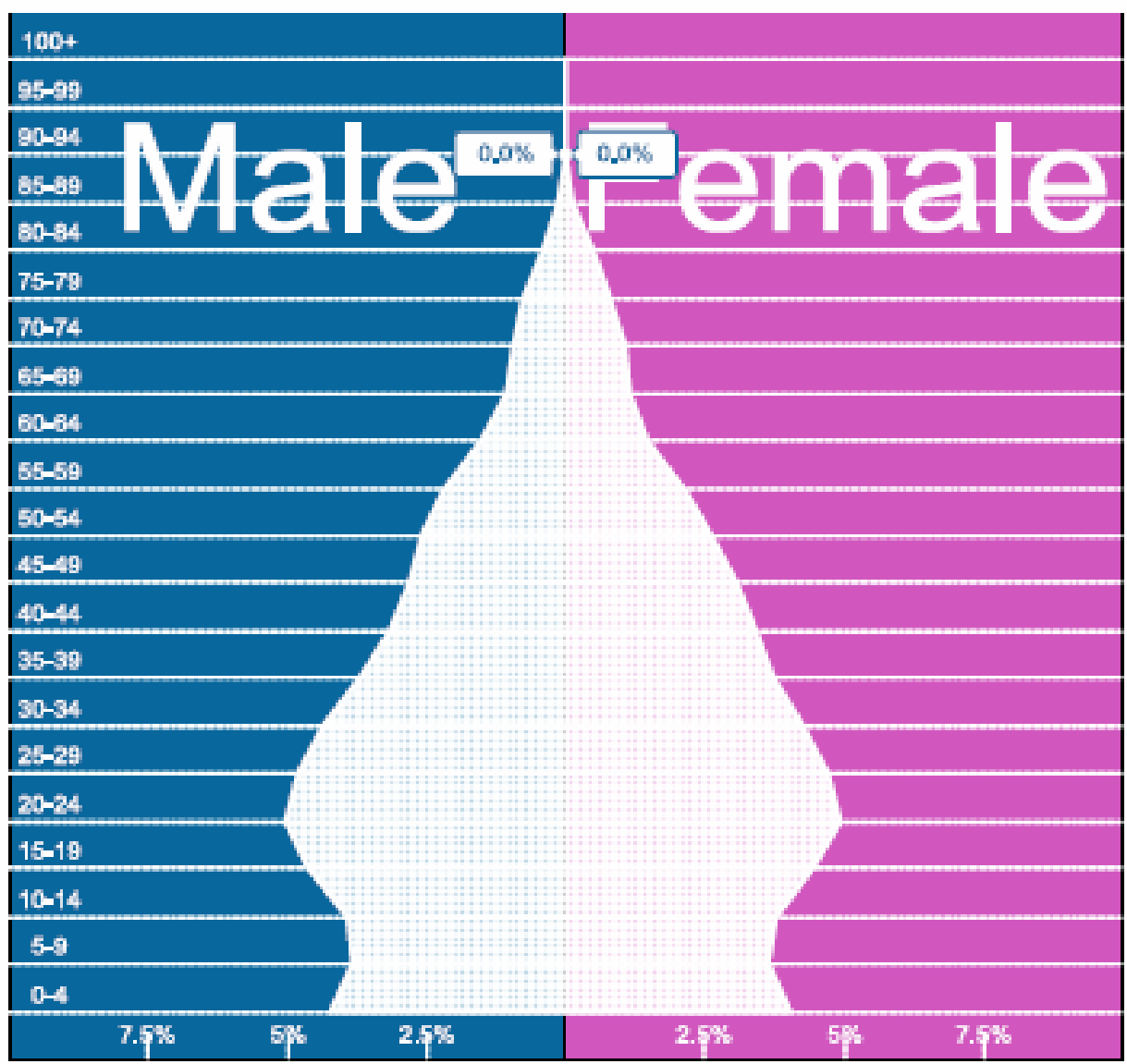

Fuente: Population Pyramid 


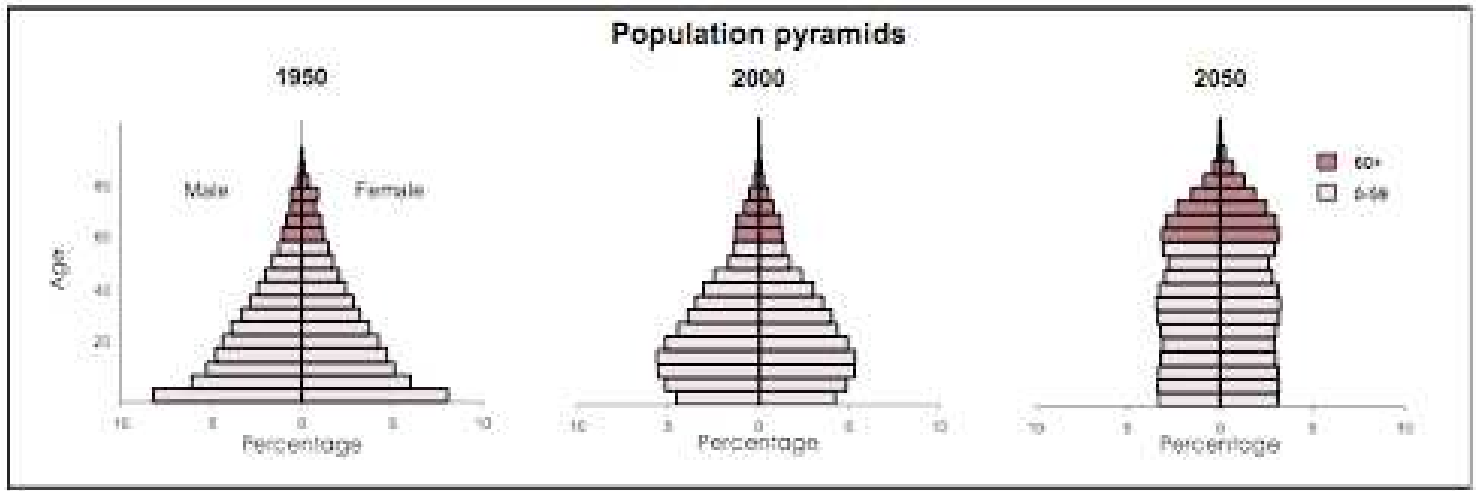

Fuente: Naciones Unidas, DESA

\subsection{La población mayor de 65 años}

De hecho, como muestra el mapa siguiente, los tres Estados que consideramos se encuentran entre los que cuentan con una población más joven en el mundo. En concreto, los tres Estados que consideramos se encuentran entre los que tienen un menor porcentaje de población mayor de 65 años tal como muestra el mapa siguiente elaborado según datos de 2009:

\section{Mapa 1. Porcentaje de población mayor de 60 años}

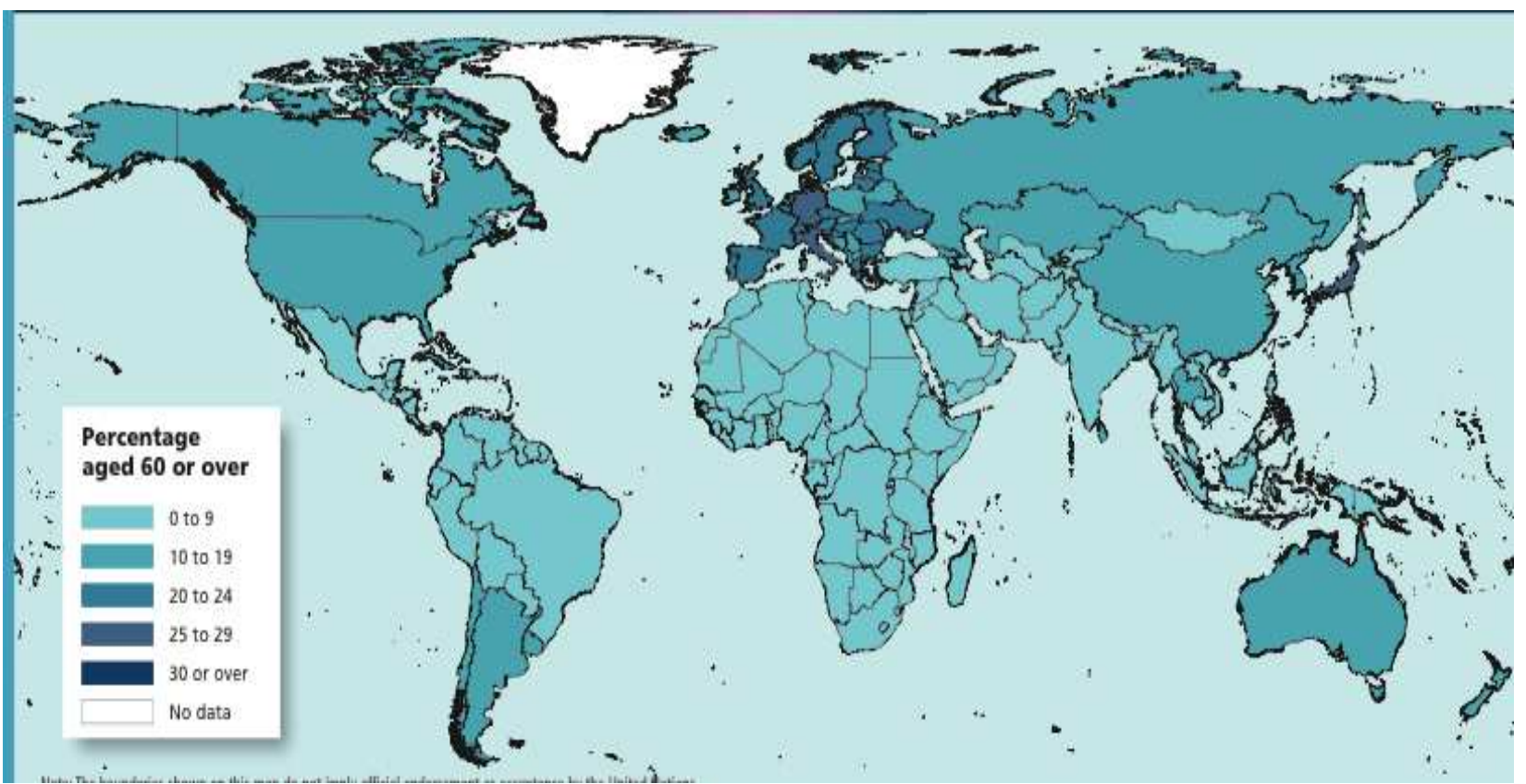

Fuente: UN DATA/PNUD

Hay que decir que, en concreto, para según el PNUD en el citado año 2009 la población mayor de 65 años en Marruecos, Argelia y Túnez era del 7\%, 7\% y 10\% del total respectivamente ${ }^{2}$.

\footnotetext{
${ }^{2}$ Datos obtenidos de United Nations Population Fund (UNFPA): "World Population Prospects, the 2010 Revision", Nueva York, UN (22 de Octubre 2010), en http://esa.un.org/wpp/Sorting-Tables/tabsorting population.htm.
} 
En ese mismo sentido y también según las previsiones del propio PNUD $^{3}$ para 2050 el volumen de población por encima de los 65 años será del $23 \%$ del total en Marruecos ${ }^{4}$, del $24 \%$ en Argelia ${ }^{5}$ y del $28 \%$ en Túnez ${ }^{6}$ y ello frente a los casos de China, Japón o Singapur que contarán con un $34 \%$, un $44 \%$ y un $40 \%$ de la población respectivamente mayor de 65 años, lo que los convertirá en Estados mucho más envejecidos que los considerados en este trabajo ${ }^{\text {? }}$.

\subsection{La población menor de 15 años}

Frente a esta situación, es interesante observar el importantísimo volumen de población menor de 15 años con que cuentan los Estados del Magreb. Así, a la altura del año 2011, el 28\% de la población de Marruecos, el $27 \%$ de la de Argelia y el $23 \%{ }^{8}$ de la de Túnez ${ }^{9}$ estaban por debajo de dicho umbral según datos del Banco Mundial.

Una situación que, de nuevo, contrasta con la de otros Estados como España, Japón, Francia, Italia o Alemania que, para ese mismo año contaban con unos porcentajes de población menor de 15 años que oscilaban entre el 13\% en el peor de los casos y el 15\% en el mejor.

Consecuencia de todo ello es la situación actual de la Youth Dependents Ratio ${ }^{10}$ observable en el Magreb, muy superior, por ejemplo, a la española. Así, mientras que esta tasa es de 39 en Marruecos, 41 en Argelia y 33 en Túnez, es de sólo 22 en España ${ }^{11}$.

\subsection{Los Estados del Magreb: ¿En transición demográfica? ${ }^{12}$}

Como hemos visto hasta aquí la situación demográfica de los Estados del Magreb no permite hablar en el momento actual de envejecimiento y no cabe esperar a corto plazo los problemas habitualmente asociados a éste ${ }^{13}$. Por el contrario, la situación en los Estados analizados es mejor que la de muchos otros Estados en el mundo y, desde luego, mucho más positiva que la de la mayor parte del mundo desarrollado. Con todo, es visible cómo algunos indicadores empiezan a cambiar y parece conveniente prestar atención a ese cambio en la tendencia ${ }^{14}$.

\footnotetext{
${ }^{3}$ UNPFA: "World Population Ageing : 1950-2050", Nueva York, UN, en http://www.un.org/esa/population/publications/worldageing19502050/.

${ }^{4}$ Ibid., pp. 336-337.

${ }^{5}$ Ibid., pp. 114-115.

${ }^{6}$ Ibid., pp. 446-447.

7 United Nations Development Programme (UNDP): “Assesing progress in Africa towards the Millenium Developtmen Goals", MDG Report (2011), en http://web.undp.org/africa/mdg/report.pdf.

8 "Tunisia by contrast, with just $23 \%$ of under 15 s has Africa's highest proportion of older adults", en Golaz, Valerie; Nowik, Laurent and Sajoux, Muriel: “Africa, a Young but ageing continent", Population \& Societies, $\mathrm{n}^{\circ}$ 491 (Julio-Agosto 2012), p. 1.

9 “2012 World Population Data Sheet”, Kaisser Family Foundation, Population Reference Bureau, disponible en http://www.prb.org/Publications/Datasheets/2012/world-population-data-sheet/data-sheet.aspx.

${ }^{10}$ La tasa mide la relación entre las personas dependientes menores de 15 y la población en edad de trabajar, entre 15 y 64 .

${ }^{11}$ La tasa es el resultado de calcular la proporción de personas dependientes que corresponden a cada 100 personas en edad de trabajar.

${ }^{12}$ Sobre transición demográfica, ver: Angeles L. :"Demographic transitions: analyzing the effects of mortality on fertility”, Journal of Population Economics, vol. 33, n⿳亠口冋 (Enero 2010).

13 "En Túnez, pero también en Argelia y en Marruecos, los efectivos del grupo de edad de los 15-24 han alcanzado un pico histórico y los que llegan al mercado de trabajo y de la vivienda no han sido jamás tan elevados", en: Larburu, Mikel: "Rápido envejecimiento en el Magreb apuestas", Fundación Sur, Africa desarrollo, 15 de Mayo de 2012, en www.africafundacion.org/spsp.php?article11629.

${ }^{14}$ African Development Bank Group: "Africa’s Demographic Trends", Briefing Note, no 4 (Marzo 2012), en
} 
En este sentido parece que, aunque lenta al menos por el momento, empieza a producirse una transición demográfica en el Magreb. Así, el descenso de los índices de mortalidad y la estabilización de los índices de nacimientos no serían sino los indicadores más destacados de un proceso lento que parece conducir a escenarios de envejecimiento para el último tercio del siglo XXI.

La gráfica y los datos que mostramos a continuación dan cuenta de esa tendencia al decrecimiento del número de nacimientos en los tres Estados:

\section{Gráfico 1. Nacimientos ${ }^{15} / 1000$ habitantes en los Estados del Magreb central}

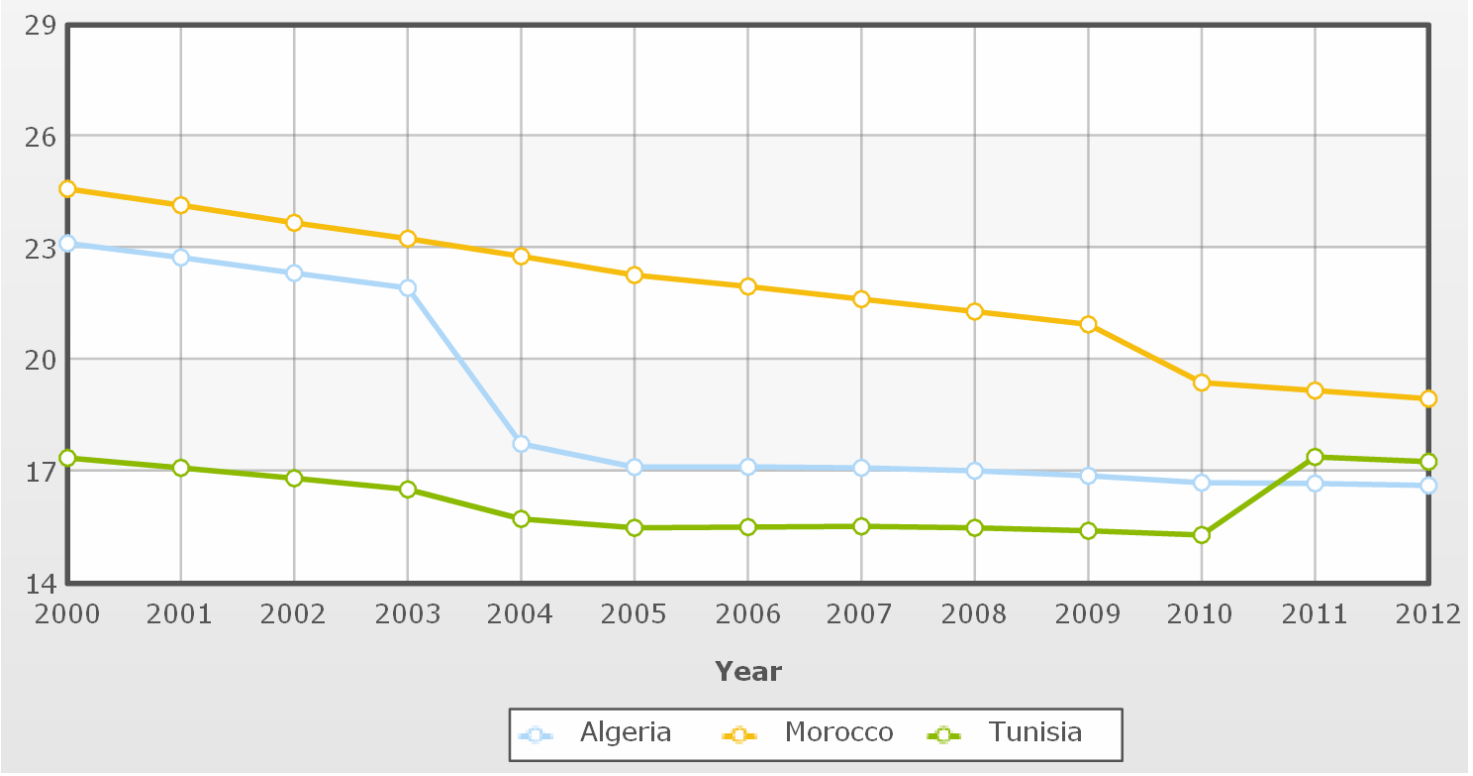

Fuente: Index Mundi

\begin{tabular}{|l|l|l|l|l|l|l|l|l|l|l|l|l|l|}
\hline Países & 2000 & 2001 & 2002 & 2003 & 2004 & 2005 & 2006 & 2007 & 2008 & 2009 & 2010 & 2011 & 2012 \\
\hline Argelia & 23.14 & 22.76 & 22.34 & 21.94 & 17.76 & 17.13 & 17.14 & 17.11 & 17.03 & 16.9 & 16.71 & 16.69 & 16.64 \\
\hline Marruecos & 24.6 & 24.16 & 23.69 & 23.26 & 22.79 & 22.29 & 21.98 & 21.64 & 21.31 & 20.96 & 19.4 & 19.19 & 18.97 \\
\hline Túnez & 17.38 & 17.11 & 16.83 & 16.53 & 15.74 & 15.5 & 15.52 & 15.54 & 15.5 & 15.42 & 15.31 & 17.4 & 17.28 \\
\hline
\end{tabular}

Fuente: Index Mundi

http://www.afdb.org/fileadmin/uploads/afdb/Documents/Policy-

Documents/FINAL\%20Briefing\%20Note\%204\%20Africas\%20Demographic\%20Trends.pdf.

${ }^{15}$ Otros autores ponen el énfasis en la tasa de nacimientos, ver: Becker G.S. (1960): "An economic analysis of fertility", en National Bureau Conference: Demographic and economic change in developed countries, National Bureau Conference series $n^{\circ}$ 10, Princeton, Princeton University Press. 
De igual modo, la tasa de fecundidad evoluciona en el mismo sentido, tal como muestra el gráfico siguiente:

Gráfico 2. Evolución de la Tasa de Fecundidad (hijos/mujer) en los Estados del Magreb central

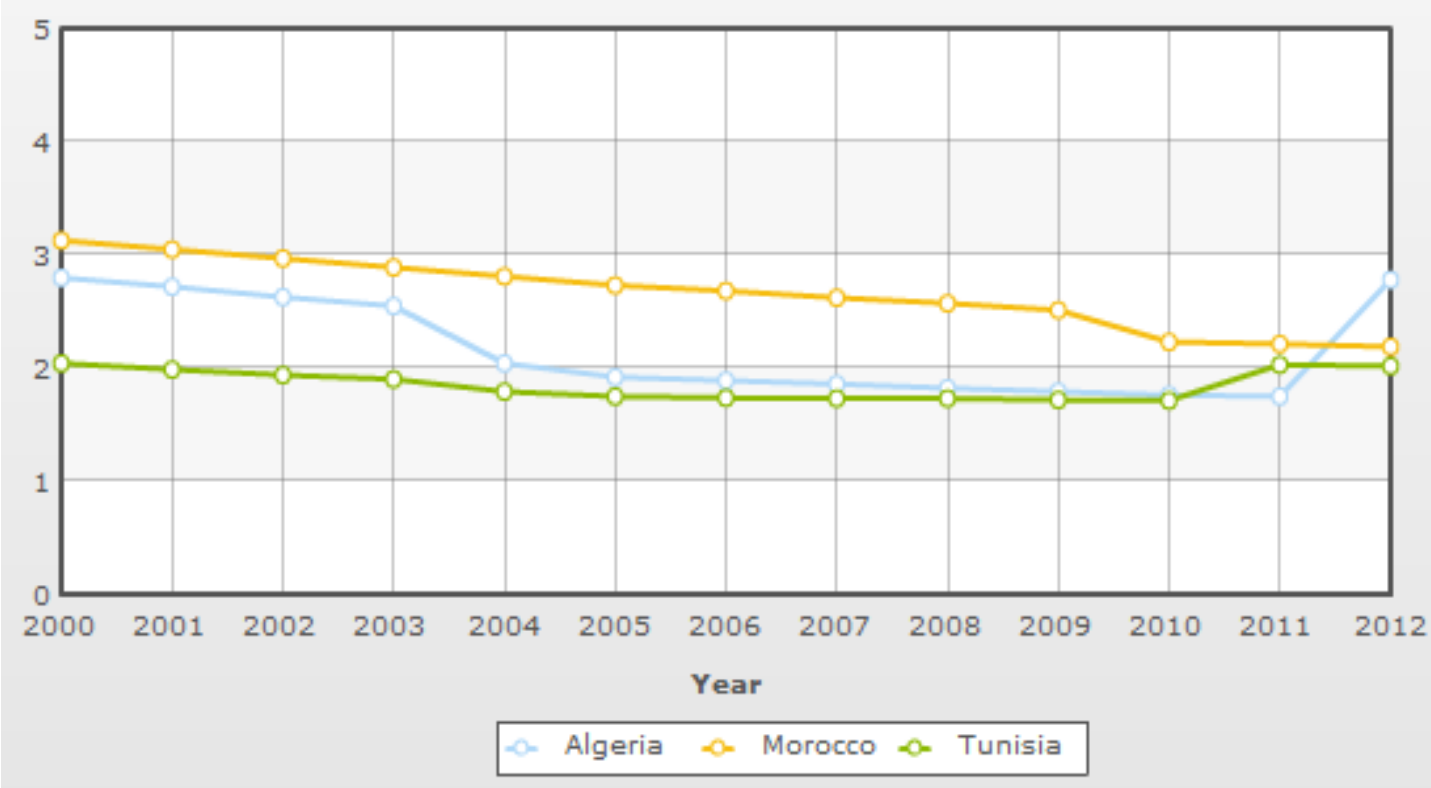

Fuente: Index Mundi

\begin{tabular}{|c|r|r|r|r|r|r|r|r|r|r|r|r|r|}
\hline País & $\mathbf{2 0 0 0}$ & $\mathbf{2 0 0 1}$ & $\mathbf{2 0 0 2}$ & $\mathbf{2 0 0 3}$ & $\mathbf{2 0 0 4}$ & $\mathbf{2 0 0 5}$ & $\mathbf{2 0 0 6}$ & $\mathbf{2 0 0 7}$ & $\mathbf{2 0 0 8}$ & $\mathbf{2 0 0 9}$ & $\mathbf{2 0 1 0}$ & $\mathbf{2 0 1 1}$ & $\mathbf{2 0 1 2}$ \\
\hline Argelia & 2.8 & 2.72 & 2.63 & 2.55 & 2.04 & 1.92 & 1.89 & 1.86 & 1.82 & 1.79 & 1.76 & 1.75 & 2.78 \\
\hline Marruecos & 3.13 & 3.05 & 2.97 & 2.89 & 2.81 & 2.73 & 2.68 & 2.62 & 2.57 & 2.51 & 2.23 & 2.21 & 2.19 \\
\hline Túnez & 2.04 & 1.99 & 1.94 & 1.9 & 1.79 & 1.75 & 1.74 & 1.73 & 1.73 & 1.72 & 1.71 & 2.03 & 2.02 \\
\hline
\end{tabular}

Fuente: Index Mundi 
Por otra parte, en el gráfico siguiente queda patente la evolución de los fallecimientos en los Estados considerados:

\section{Gráfico 3. Fallecimientos ${ }^{16} / 1000$ habitantes en los Estados del Magreb central}

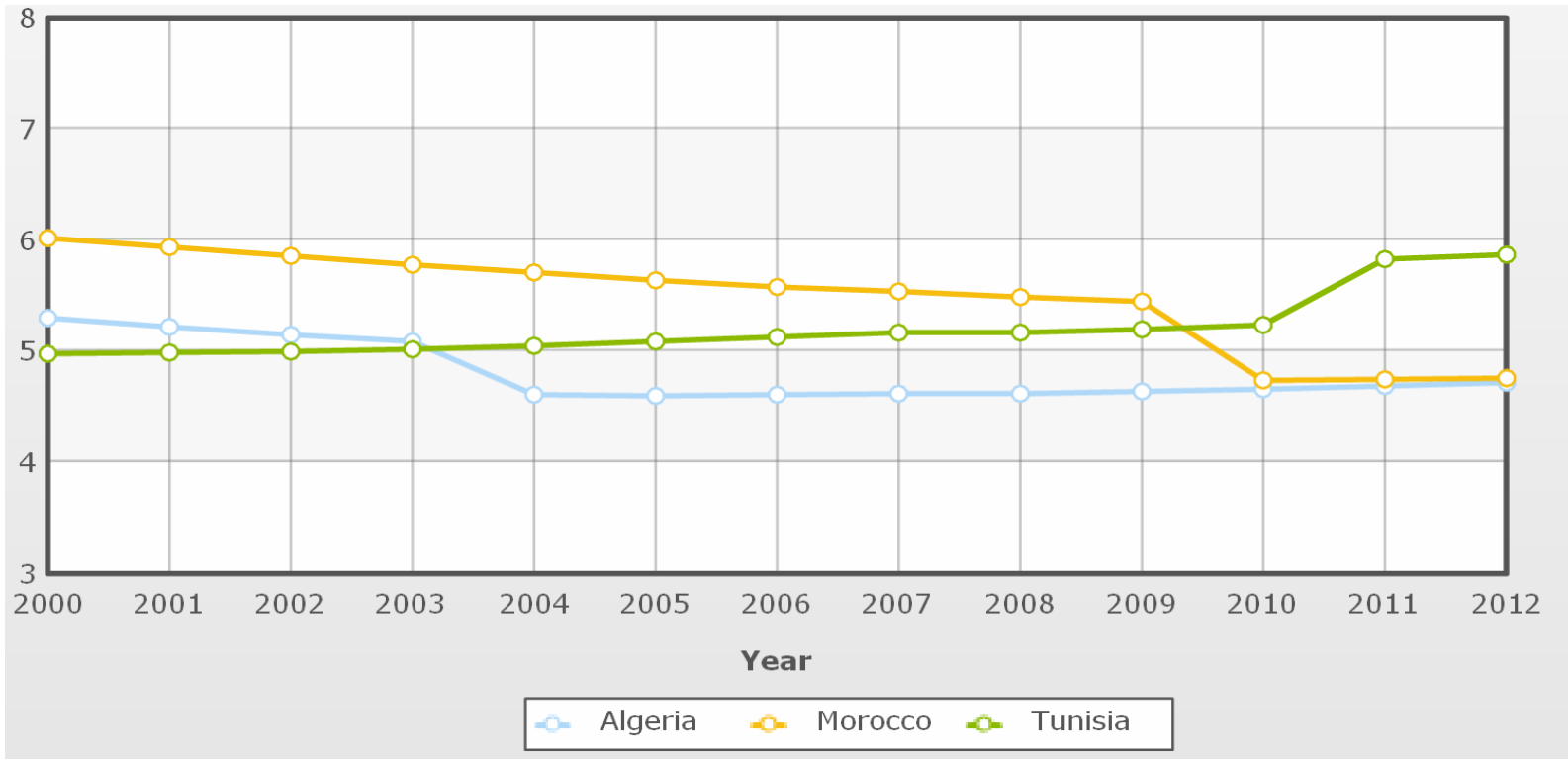

Fuente: Index Mundi

\begin{tabular}{|c|c|c|c|c|c|c|c|c|c|c|c|c|c|}
\hline País & $\mathbf{2 0 0 0}$ & $\mathbf{2 0 0 1}$ & $\mathbf{2 0 0 2}$ & $\mathbf{2 0 0 3}$ & $\mathbf{2 0 0 4}$ & $\mathbf{2 0 0 5}$ & $\mathbf{2 0 0 6}$ & $\mathbf{2 0 0 7}$ & $\mathbf{2 0 0 8}$ & $\mathbf{2 0 0 9}$ & $\mathbf{2 0 1 0}$ & $\mathbf{2 0 1 1}$ & $\mathbf{2 0 1 2}$ \\
\hline Argelia & 5.3 & 5.22 & 5.15 & 5.09 & 4.61 & 4.6 & 4.61 & 4.62 & 4.62 & 4.64 & 4.66 & 4.69 & 4.72 \\
\hline Marruecos & 6.02 & 5.94 & 5.86 & 5.78 & 5.71 & 5.64 & 5.58 & 5.54 & 5.49 & 5.45 & 4.74 & 4.75 & 4.76 \\
\hline Túnez & 4.98 & 4.99 & 5 & 5.02 & 5.05 & 5.09 & 5.13 & 5.17 & 5.17 & 5.2 & 5.24 & 5.83 & 5.87 \\
\hline
\end{tabular}

Fuente: Index Mundi

Una tendencia que, lejos de remitir, se acentuará teniendo en cuenta los datos de la evolución de la esperanza de vida al nacer que mostramos en el gráfico siguiente:

\footnotetext{
${ }^{16}$ Entre los autores que basan la Transición Demográfica en los Índices de Mortalidad encontramos a: Cervellati M., Sunde U.: "Human capital formation, life expectancy and the process of economic development", American Economic Review, vol. 95, nº 5 (2005), pp. 1653-1672.
} 


\section{Gráfico 4. Evolución de la esperanza de vida al nacer en los Estados del Magreb central}

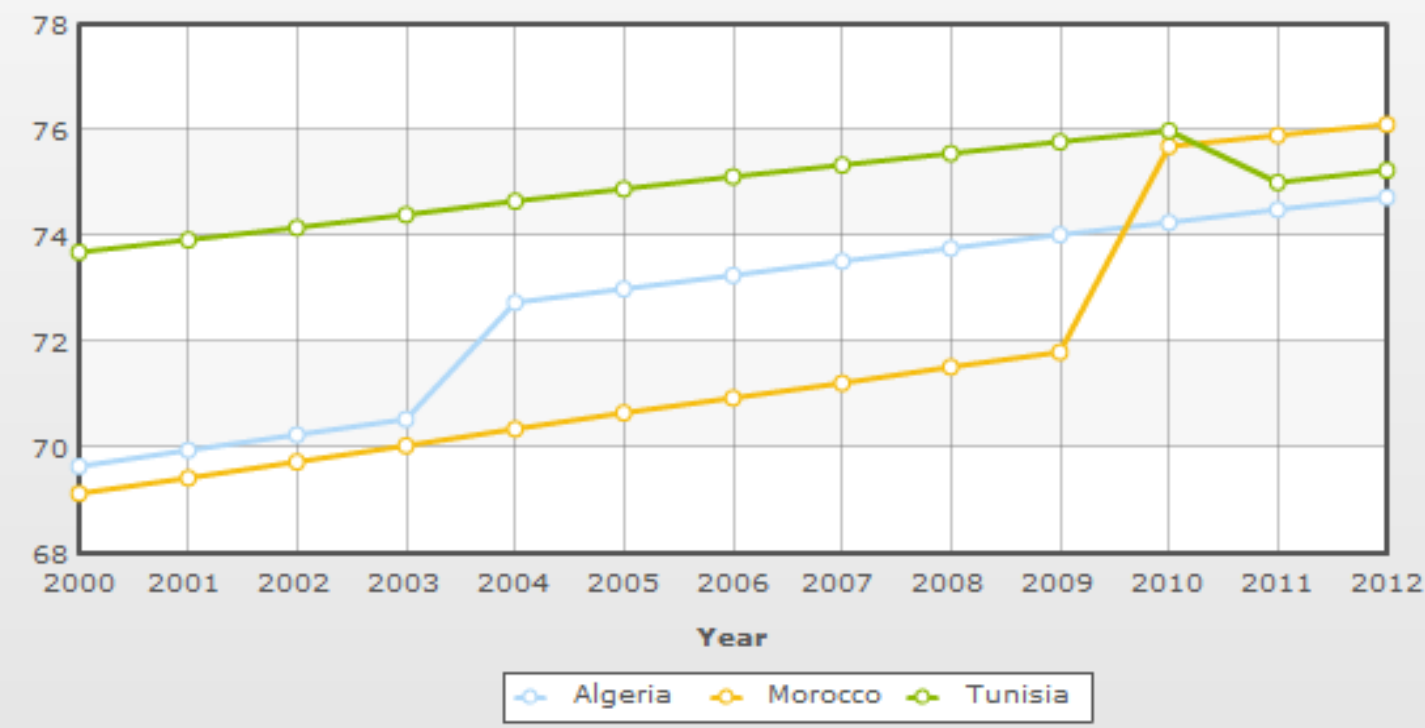

Fuente: Index Mundi

\begin{tabular}{|c|c|c|c|c|c|c|c|c|c|c|c|c|c|}
\hline País & $\mathbf{2 0 0 0}$ & $\mathbf{2 0 0 1}$ & $\mathbf{2 0 0 2}$ & $\mathbf{2 0 0 3}$ & $\mathbf{2 0 0 4}$ & $\mathbf{2 0 0 5}$ & $\mathbf{2 0 0 6}$ & $\mathbf{2 0 0 7}$ & $\mathbf{2 0 0 8}$ & $\mathbf{2 0 0 9}$ & $\mathbf{2 0 1 0}$ & $\mathbf{2 0 1 1}$ & $\mathbf{2 0 1 2}$ \\
\hline Argelia & 69.65 & 69.95 & 70.24 & 70.54 & 72.74 & 73 & 73.26 & 73.52 & 73.77 & 74.02 & 74.26 & 74.5 & 74.73 \\
\hline Marruecos & 69.13 & 69.43 & 69.73 & 70.04 & 70.35 & 70.66 & 70.94 & 71.22 & 71.52 & 71.8 & 75.69 & 75.9 & 76.11 \\
\hline Túnez & 73.69 & 73.92 & 74.16 & 74.4 & 74.66 & 74.89 & 75.12 & 75.34 & 75.56 & 75.78 & 75.99 & 75.01 & 75.24 \\
\hline
\end{tabular}

Fuente: Index Mundi

\section{La distribución espacial de la población en los Estados del Magreb}

Por otra parte, los Estados del Magreb estarían experimentando un cambio no en cuanto al volumen o a la composición de su población sino en lo que hace a la distribución de ésta en el espacio $^{17}$.

En este sentido, sería crecientemente observable un proceso de emigración del campo a la ciudad debido principalmente a las peores condiciones de vida existentes en el campo en comparación con las ciudades ${ }^{18}$. Un dato que pondría de manifiesto esa menor calidad de vida existente en las áreas rurales sería el porcentaje de población con acceso al agua potable existente en estas áreas:

\footnotetext{
${ }^{17}$ Sobre Marruecos ver: de Hass, Hein: "International Migration and Regional Development in Morocco: A Review", Journal of Ethnic \& Migration Studies, vol. 35, no. 10 (Diciembre 2009).

${ }^{18}$ Bounoua, Lahouari et al.: "Impact of Urban Growth on Surface Climate: A Case Study in Oran, Algeria", Journal of Applied Meteorology \& Climatology, vol. 48, n 2 (Febrero 2009).
} 
Tabla1. Porcentaje de población con acceso a agua potable

\begin{tabular}{|l|l|l|l|l|l|}
\hline País & 2002 & 2004 & 2006 & 2008 & 2010 \\
\hline Argelia & $83 \%$ & $82 \%$ & $81 \%$ & $79 \%$ & $79 \%$ \\
\hline Marruecos & $58 \%$ & $59 \%$ & $60 \%$ & $61 \%$ & $61 \%$ \\
\hline Túnez & $80 \%$ & $82 \%$ & $84 \%$ & $84 \%$ & \\
\hline
\end{tabular}

Fuente: Banco Mundial

Ese proceso migratorio estaría generando una situación de envejecimiento de la población rural que no se ve acompañado por un envejecimiento simultáneo de la población urbana (véase el artículo de Eric Pardo y Nieva Machín en esta misma revista).

Ahora bien, la capacidad de las ciudades para absorber esas poblaciones es, cuando menos dudosa. Y ese sería probablemente un factor a tener en cuenta al evaluar la evolución de las tasas de desempleo o migratoria de los Estados magrebíes.

\subsection{El desempleo}

Por otra parte los Estados del Magreb serían crecientemente excedentarios en términos de población activa. Dicho de otro modo, no cuentan con una economía lo suficientemente importante y desarrollada como para absorber su fuerza de trabajo.

\section{Gráfico 5. Población activa en los Estados del Magreb central}

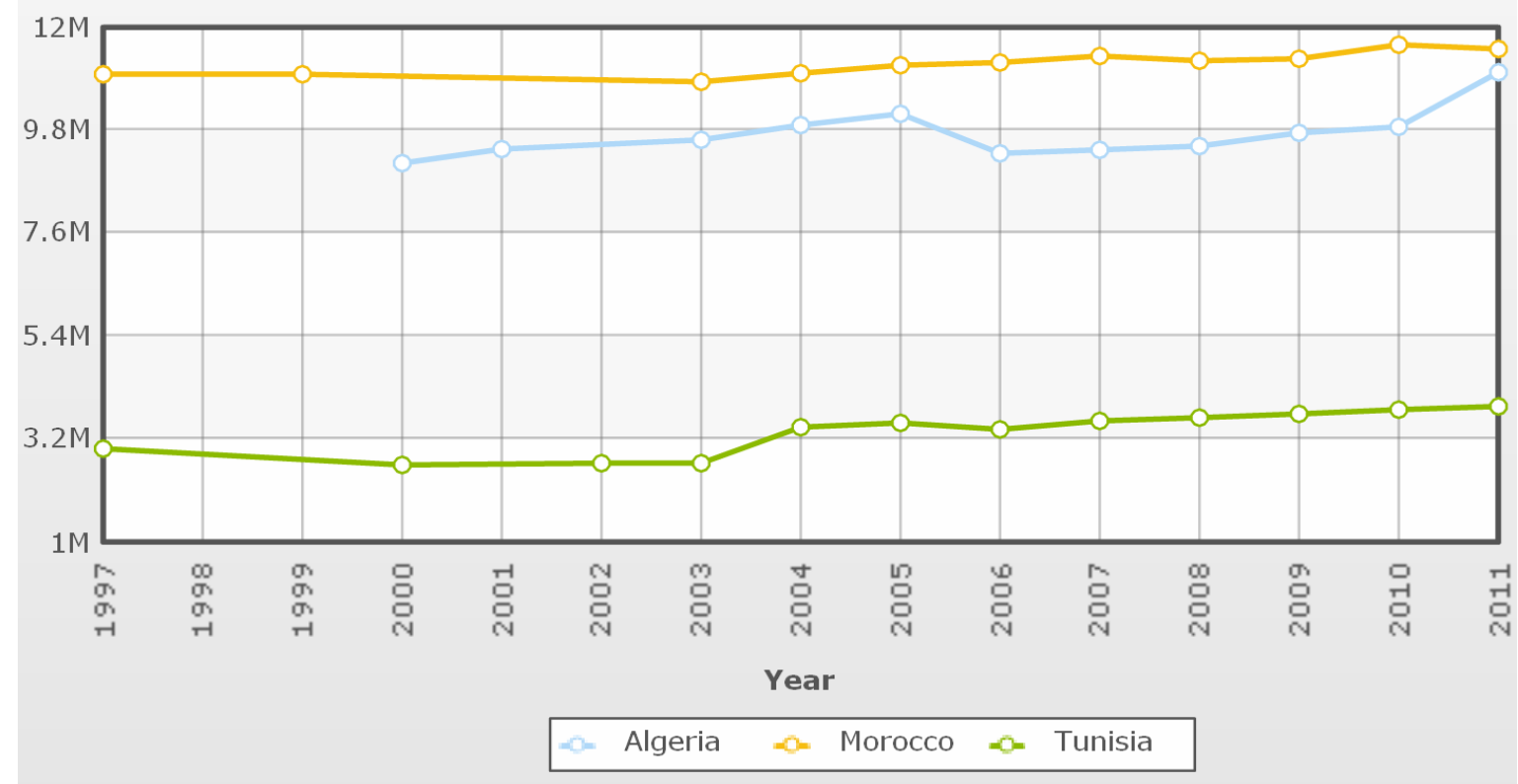

Fuente: Index Mundi 
Esta realidad contribuye a explicar la existencia de tasas de desempleo elevadas -del $9 \%$ en Marruecos, el 10\% en Argelia e, incluso el 17\% en Túnez:

Gráfico 6. Evolución Tasa de Desempleo en los Estados del Magreb central

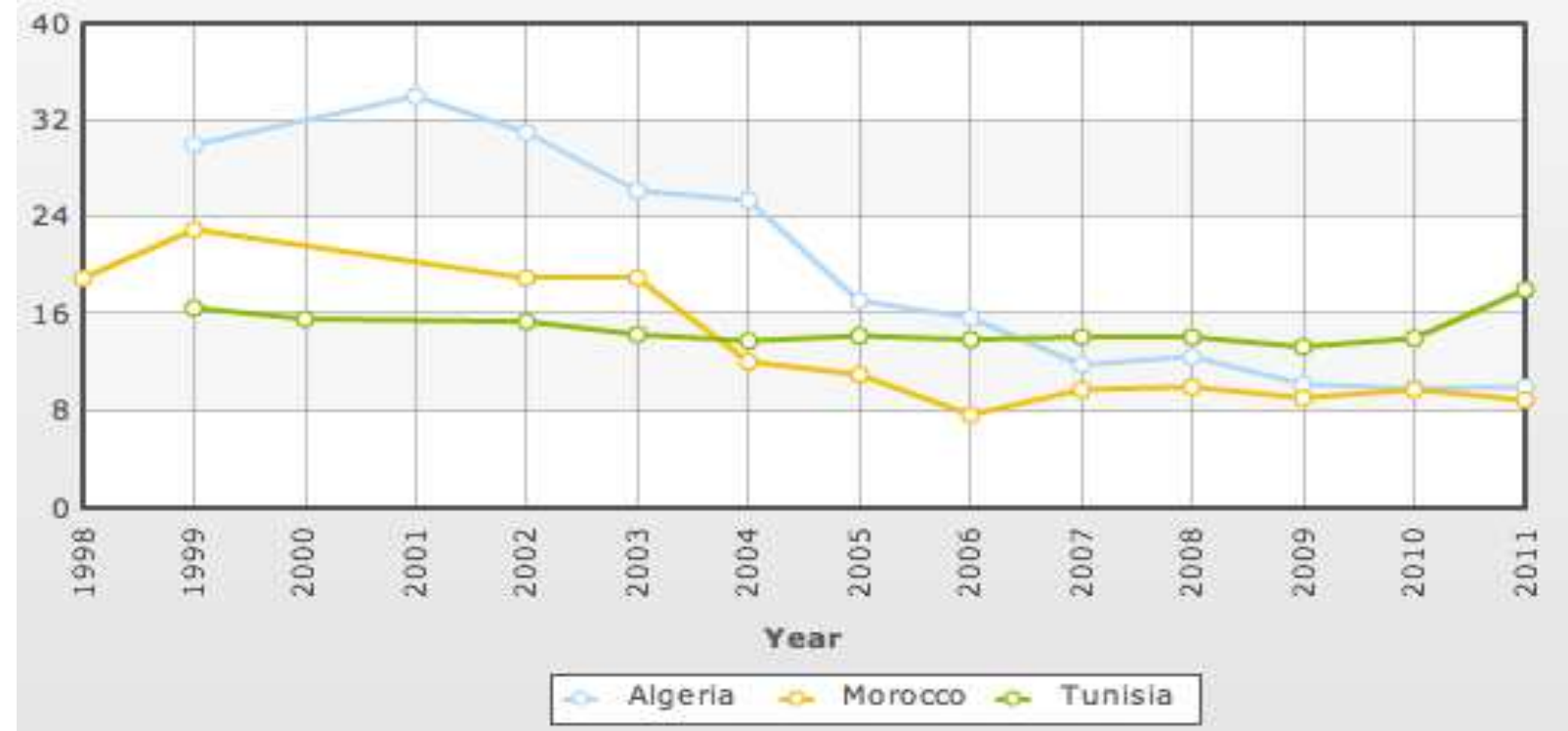

Fuente: Index Mundi

El desempleo afecta a la población urbana y a la población rural. La agricultura emplea aproximadamente a la tercera parte de los trabajadores de Marruecos y a la cuarta parte de los trabajadores de Túnez y Argelia, y es precisamente esta población rural la más vulnerable, dado su alto nivel de analfabetismo, la falta de servicios básicos, como la educación, que permitan su promoción, la precariedad de sus empleos y los bajos salarios. En el caso de la población urbana, hay que reseñar de forma especial que en todos los Estados del Magreb la inserción laboral de los jóvenes que han obtenido una titulación es baja. En general, se puede decir que la tasa de paro existente en diversas ciudades, entre las personas con un nivel educativo superior, es muy elevada.

Todo esto permite explicar asimismo la existencia de un importante volumen de población por debajo del umbral de la pobreza, especialmente en Argelia y Túnez, -por este orden-, y en mucha menor medida, aunque también reseñable, en Marruecos ${ }^{19}$.

\subsection{La emigración}

Por lo demás, también sería un elemento que alimentaría saldos migratorios permanentemente negativos en los Estados considerados (véase el artículo de Gloria Inés Ospina en esta misma revista):

\footnotetext{
${ }^{19}$ Brian, Edward: "The Maghreb in Black and White", Foreign Policy, no 146 (Ene./Feb. 2005).
} 


\section{Gráfico 7. Tasa de Emigración/1000 habitantes en los Estados}

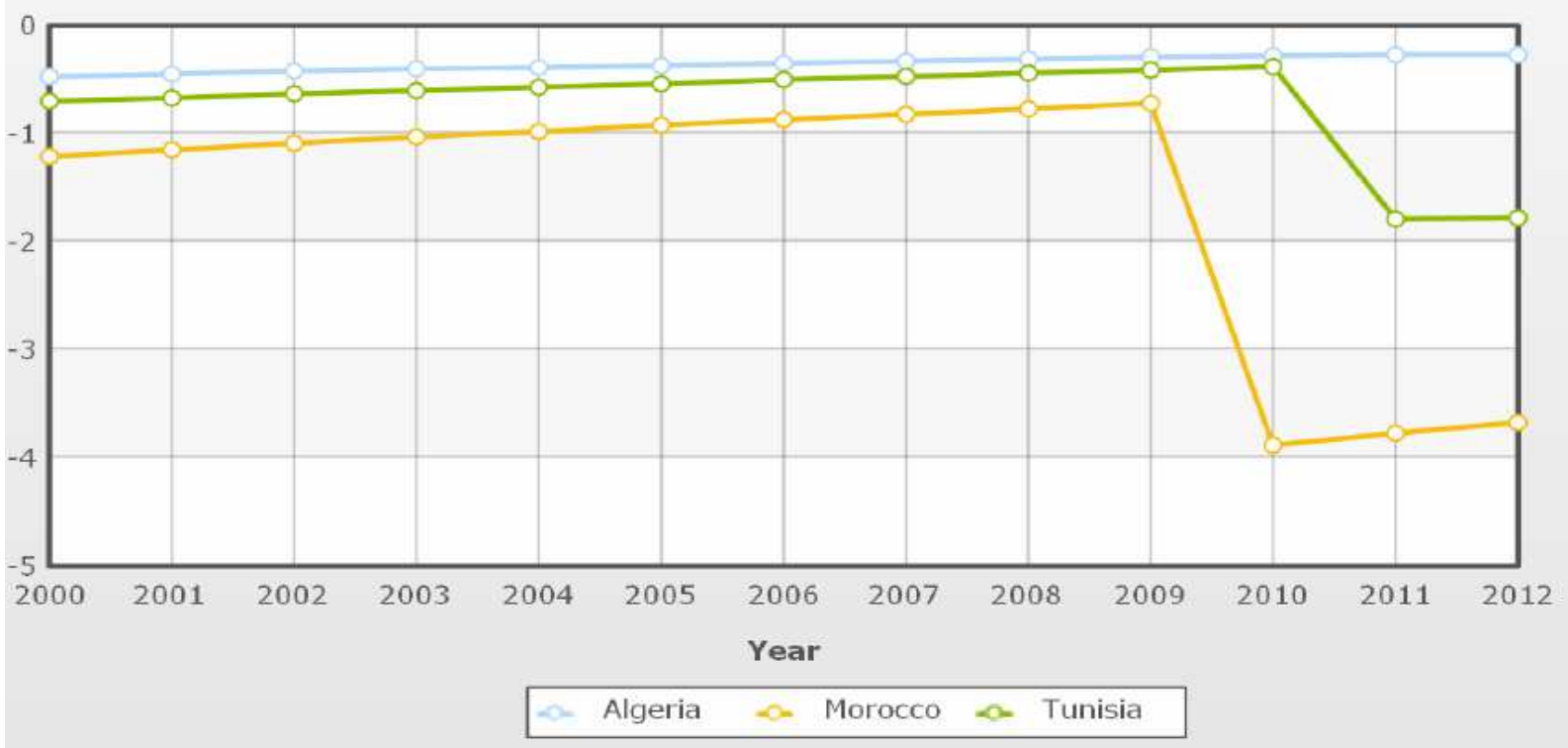

Fuente: Index Mundi

\begin{tabular}{|l|l|l|l|l|l|l|l|l|l|l|l|l|l|}
\hline País & 2000 & 2001 & 2002 & 2003 & 2004 & 2005 & 2006 & 2007 & 2008 & 2009 & 2010 & 2011 & 2012 \\
\hline Argelia & -0.47 & -0.45 & -0.42 & -0.4 & -0.39 & -0.37 & -0.35 & -0.33 & -0.31 & -0.29 & -0.28 & -0.27 & -0.27 \\
\hline Marruecos & -1.21 & -1.15 & -1.09 & -1.03 & -0.98 & -0.92 & -0.87 & -0.82 & -0.77 & -0.72 & -3.88 & -3.77 & -3.67 \\
\hline Túnez & -0.7 & -0.67 & -0.63 & -0.6 & -0.57 & -0.54 & -0.5 & -0.47 & -0.44 & -0.41 & -0.38 & -1.79 & -1.78 \\
\hline
\end{tabular}

Fuente: Index Mundi

\section{Conclusiones}

En resumen, no cabe considerar que en la actualidad haya un proceso generalizado de envejecimiento en los Estados del Magreb, pese a que a largo plazo sí podría abrirse paso un escenario de esas características pues el proceso de envejecimiento en estos países incluyendo todos los Estados árabes mediterráneos es de los más rápidos del mundo en la actualidad y se calcula que la media de edad pasará de 20 años en 1990 a 30 años en el $2020^{20}$.

Sin embargo, sí es observable en el área que nos ocupa un progresivo deterioro de las condiciones de vida existentes en las zonas rurales, deterioro que es tanto más importante en términos relativos, esto es, por comparación con la evolución experimentada por la calidad de vida en las áreas urbanas.

Ese empeoramiento relativo es con toda probabilidad el principal factor a tener en cuenta al valorar el proceso existente de emigración del campo a la ciudad, un proceso que

\footnotetext{
${ }^{20}$ Abis Sébastien (2012): Pour le futur de la Méditerranée :l'agriculture, L'Harmattan, p 19.
} 
estaría sumando al deterioro relativo de las condiciones de vida existentes en el campo el envejecimiento relativo de las áreas rurales por comparación con las áreas urbanas, tal como se expone en otros estudios de esta revista.

En consecuencia, dado el crecimiento de la población, es previsible un incremento sostenido de la demanda de alimentos en todos estos Estados y, dada la situación de deterioro apreciable en el mundo rural, la respuesta por parte de la oferta productiva de estos Estados será claramente insuficiente, por lo que se imponen políticas mucho más efectivas y costosas que permitan mantener la población dedicada a la agricultura, evitar su envejecimiento y fomentar su productividad. 